Article Code: 0240/2019/RALF

Res. Agric. Livest. Fish.

Article Type: Original Research

Vol. 6, No. 2, August 2019 : 315-322.

\title{
PREVALENCE OF Dirofilaria immitis IN THE CARNIVORES AND ITS VECTORS IN MYMENSINGH MUNICIPAL AREA OF BANGLADESH
}

\section{Quazi Mustain Billah', Md. Abdul Karim², Md. Billal Hossain ${ }^{2}$, Pallab Kumar Dutta ${ }^{3}$ and Md Hasanuzzaman Talukder ${ }^{2 *}$}

${ }^{1}$ Upazila Livestock Officer, Department of Livestock Service, Govt. of Bangladesh; ${ }^{2}$ Department of Parasitology, Faculty of Veterinary Science, Bangladesh Agricultural University, Mymensingh-2202, Bangladesh; ${ }^{3}$ Assistant Director, Department of Livestock Service, Govt. of Bangladesh.

*Corresponding author: Md. Hasanuzzaman Talukder; E-mail: talukdermhasan@bau.edu.bd

\section{ARTICLE INFO}

Received

17 May, 2019

Revised

19 August, 2019

Accepted

27 August, 2019

Online

31 August, 2019

Key words

Dirofilaria

Heartworm

Prevalence

Vectors

Bangladesh

\section{A B S T R A C T}

Heartworm is a global problem caused by Dirofilaria immitis that occurs in some carnivores in tropics and subtropics including some temperate countries. There is also a public health implication, since infection in human is occasionally reported. We investigated the prevalence of $D$. immitis among carnivores and to identify its vectors and to correlate between them in the study area. We examined the prevalence of $D$. immitis in stray dogs, wild foxes, and community cats, and in their vectors in Mymensingh Municipal Area. In this study, following the guidelines of the animal welfare and experimentation ethical committee, euthanized animals and mosquitoes were investigated for adult parasites and microfilariae, respectively. Among animals investigated $56.0 \%$ of dogs and $71.4 \%$ of foxes and none of cats were infected with $D$. immitis. Infection in animal below 2 years of age were $46.1 \%$ and $66.6 \%$ in dogs and foxes respectively compared to $66.6 \%$ and $75.0 \%$ infection respectively in dogs and foxes above 2 years of age. In male the rate of infections were $61.5 \%$ in dogs and $75.0 \%$ in foxes compared to $50.0 \%$ in female dogs and $66.66 \%$ in female foxes. Microfilariae were detected in $44 \%$ dogs and $57.14 \%$ foxes examined. The Culex sp. had $11.3 \%$ and the Anopheles sp. had 6.1\% infection, whereas none of the Aedes sp had any microfilariae. Since these dogs and foxes live near the human habitations in study area, it was considered a serious public health threat to humans. Because of both veterinary and public health significance, further detailed studies on the prevalence of $D$. immitis in Bangladesh are highly emphasized.

To cite this article: Billah QM, MA Karim, MB Hossain, PK Dutta and MH Talukder, 2019. Prevalence of Dirofilaria immitis in the carnivores and its vectors in Mymensingh municipal area of Bangladesh. Res. Agric. Livest. Fish. 6 (2): 315-322.

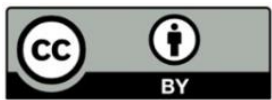




\section{INTRODUCTION}

Canine heartworm is now a serious problem throughout the world. Dirofilaria immitis (Nematoda: Filaridiae) occurs in the dog, cat, fox and wolf in tropics and subtropics and in some temperate countries (Soulsby, 1982) and wild canids harbor important reservoir. D. immitis establishes itself in human and causes severe consequences (Saito et al., 1995, Smith et. al., 1998). The worms live mainly in the right ventricle and the pulmonary artery, but have also been found in other parts of the body such as lungs and its adjacent vessels (Smith et. al., 1998. The intermediate hosts are usually the mosquitoes of the genera Culex, Anopheles, Aedes those maintain the developmental stages of the D. immitis (Soulsby, 1982). Many dogs may be infected with $D$. immitis without showing any clinical signs of infection other than microfilarae in the blood. The prevalence of all types of heart disease in the domestic canine population is very common. However, in areas where heartworms are endemic the prevalence of heart disease may be greater. In heavy infections, however, the worms cause circulatory distress, due to mechanical interference and progressive endocarditis (Soulsby 1982). In large numbers they interfere with the function of the heart valves with resultant compensatory hypertrophy of the right ventricle and eventually result in congestive heart failure and chronic passive congestion manifested by liver enlargement, ascites and occasionally peripheral oedema (Soulsby, 1982). There is also public health implications of heartworm of dogs, since human infection with Dirofilaria sp. is occasionally reported, most have been recovered from sub-cutaneous tissues of the upper extremities in man, e.g. trunk, face, orbit or conjunctiva and heart; most specimens are immature with mild inflammation and nodule formation around the worm with high eosinophilia (Belding, 1965). ,the infection of D. immitis in carnivores in Mymensingh Municipal Area, vectors and (3) correlated its prevalence in the infection in carnivores with that vectors in the area studied.

\section{MATERIALS AND METHODS}

\section{Animal ethical statement}

The study plan was approved by the animal welfare and experimentation ethical committee (AWEEC/BAU/19).

\section{Euthanasia and Post-mortem}

The study was carried out in Mymensingh Municipal Area of Bangladesh and 25 dogs, 15 cats and 7 foxes mostly adults and belonged to local breeds (street dogs, community cats and wild foxes) were examined. The age of the animals were determined based on teeth of the dead /euthanized carnivores. The animals were euthanized by direct intra-cardial injection of saturated solution of Magnesium Sulphate (MgSo4. $5 \mathrm{H} 2 \mathrm{O}$ ) between the 4th or 5th intercostal space. The carcasses were following the standard procedure of post-mortem examination as described by Cable (Cable, 1953) and the heart, right ventricle, pulmonary artery, aorta and lungs were removed, and examined thoroughly petridish/glass jars. The chambers of the heart, aorta and pulmonary artery were opened carefully.

\section{Collection and identification of parasites}

The parasites were collected with the help of curved needles and were put on the petridish containing normal saline. Collected parasites were cleared off blood preserved in glycerine alcohol (Glycerine 5 parts and $75 \%$ alcohol 95 parts). Parasites were identified by preparing temporary slides by adding one drop of lukewarm lactophenol following the keys and description published elsewhere (Belding, 1965; Soulsby, 1982).

\section{Detection of microfilariae from blood}

The peripheral blood from trapped carnivores was collected in clean vials premedicated with anticoagulants (Ca-EDTA). A drop of blood was taken on the slide and mixed with a drop of normal saline and wet smears were examined under microscope for detecting living microfilariae made and stained. Giemsa's stain slides were examined under microscope using 100X objective by adding oil immersion blood was preserved by adding $2 \%$ formalin for further use. 


\section{Examination of mosquitoes and identification of microfilariae}

For vector studies, 1910 mosquitoes of Culex sp. Anopheles sp. and Aedes sp. and about 23 Ctenocephalides canis fleas and examined (Chandler and Read, 1961). Vectors were identified using the descriptions (Belding, 1965; Soulsby, 1982). With intention At least 10 mosquitoes from each collection was taken on a slide and dissected in a few drops of saline using needles and examined under the microscope using objectives 40x. Microfilariae those showing movement were examined under oil immersion using objectives up to 100x. Similarly 23 fleas were examined and identified. icrofilariae were identified following the keys description published previously (Belding, 1965; Soulsby, 1982).

\section{Statistical analysis}

Statistical analysis was made to determine the number of infected dogs, cats, and foxes within their respective population. Similarly, the number of mosquitoes infected from the population of each genera were determined, correlation coefficient was determined to relate infectivity of microfilarial prevalent in different genera of mosquitoes using standard methods (Chi-squre Test) (Swaroop et al., 1966).

\section{RESULTS}

D. immitis was detected in the right ventricle of 14 (56\%) dogs, 5 (71.4\%) foxes and none of 15 cats (Table1). A maximum of 18 parasites (10 females and8 males) were recorded in a dog where the parasites were also found in the pulmonary artery and the minimum number recoded was 3 ( 2 females and 1 Male). Likewise maximum number of parasites collected from fox was 13 ( 9 Females) and 4 Males) and minimum 2 (1 Female) and 1 Male), respectively (Figures 1 and 2 ). We found that $s 61.5 \%$ male dogs $75.0 \%$ male foxes were infected with parasite (Table 3). First stage microfilariae ( $\mathrm{mf} 1$ ) were detected in (Figure 3) $44.0 \%$ dogs and $57.14 \%$ foxes (Table 4 ).

Table 1. Prevalence of $D$. immitis in carnivores in Mymensingh Municipal area

\begin{tabular}{|lll|}
\hline Animals & $\begin{array}{l}\text { Number of Animals } \\
\text { Examined( N) }\end{array}$ & Percentage of infections (\%) \\
\hline Dog & 25 & 56 \\
Cat & 15 & 0 \\
Fox & 7 & 71.42 \\
\hline
\end{tabular}

Table 2. Age wise frequency distribution of $D$. immitis in carnivores in Mymensingh Municipal area

\begin{tabular}{|lllll|}
\hline Animals & $\begin{array}{l}\text { Animals up to 2 years } \\
\text { examined (N) }\end{array}$ & $\begin{array}{l}\text { Percent of } \\
\text { Infection (\%) }\end{array}$ & $\begin{array}{l}\text { Animals above 2 } \\
\text { years examined }\end{array}$ & $\begin{array}{l}\text { Percentage of } \\
\text { infection (\%) }\end{array}$ \\
\hline Dog & 13 & 46.1 & 12 & 66.6 \\
Cat & 8 & 0 & 7 & 0 \\
Fox & 3 & 66.6 & 4 & 75.0 \\
\hline
\end{tabular}

Dog $=$ Probability $0.5293, P>0.05$ Non significant

Foxes $=$ Probability $0.5460, \mathrm{P}>0.05$ Non significant 
Table 3. Sex wise distribution of $D$. immitis in carnivores in Mymensingh Municipal area

\begin{tabular}{|llll|}
\hline Animals & Sex & Total Number of Animal examined (N) & Percentage of infections (\%) \\
\hline \multirow{2}{*}{ Dog } & Male & 13 & 61.53 \\
& Female & 12 & 50 \\
Cat & Male & 9 & 0 \\
& Female & 6 & 0 \\
Fox & Male & 4 & 75 \\
& Female & 3 & 66.66 \\
\hline
\end{tabular}

Dog $=$ Probability $0.8592, P>0.05$ Non significant

Foxes $=$ Probability $0.5460, P>0.05$ Non significant

Table 4. Percentage of microfilariae (mf) in the carnivore's blood

\begin{tabular}{|lll|}
\hline Species of carnivores & Number of carnivores Examined (N) & Percentage of positive cases (\%) \\
\hline Dog & 25 & 44 \\
Cat & 15 & 0 \\
Fox & 7 & 57.14 \\
\hline
\end{tabular}

Dog $=$ Probability $0.0000, P<0.01$ Significant

Foxes $=$ Probability $0.0000, P<0.01$ Significant

Table 5. Identification of Mosquitoes

\begin{tabular}{|lllll|}
\hline $\begin{array}{l}\text { Species of } \\
\text { Mosquitoes } \\
\text { Examined }\end{array}$ & $\begin{array}{l}\text { Number of } \\
\text { Mosquitoes } \\
\text { Collected }\end{array}$ & $\begin{array}{l}\text { Number of } \\
\text { Examined }\end{array}$ & $\begin{array}{l}\text { Number of } \\
\text { Infected Cases }\end{array}$ & $\begin{array}{l}\text { Percentage of } \\
\text { positive cases (\%) }\end{array}$ \\
\hline Culex $s p$ & 1030 & 115 & 13 & 11.3 \\
Anopheles $s p$ & 670 & 49 & 3 & 6.1 \\
Aedes $s p$ & 210 & 20 & 0 & 0 \\
\hline
\end{tabular}

Culex $s p=$ Probability $0.0000, \mathrm{P}<0.01$ Significant; Anopheles $s p=$ Probability $0.0000, \mathrm{P}<0.01$ Significant

Of the 1910 mosquitoes belonging to the genera Culex sp. Anopheles sp. and Aedes sp., only 184 female mosquitoes; Culex (115), Anopheles (49) and Aedes (20); were examined, and mf3 were detected in $11.3 \% 6.1 \%$ and $0.0 \%$ mosquitoes, respectively (Figure 4 ). In all cases $\mathrm{mf}$ were detected in the thoracic muscles and proboscis (Table 5). Further none of the Ctenocephalids canis were found positive to mf. 

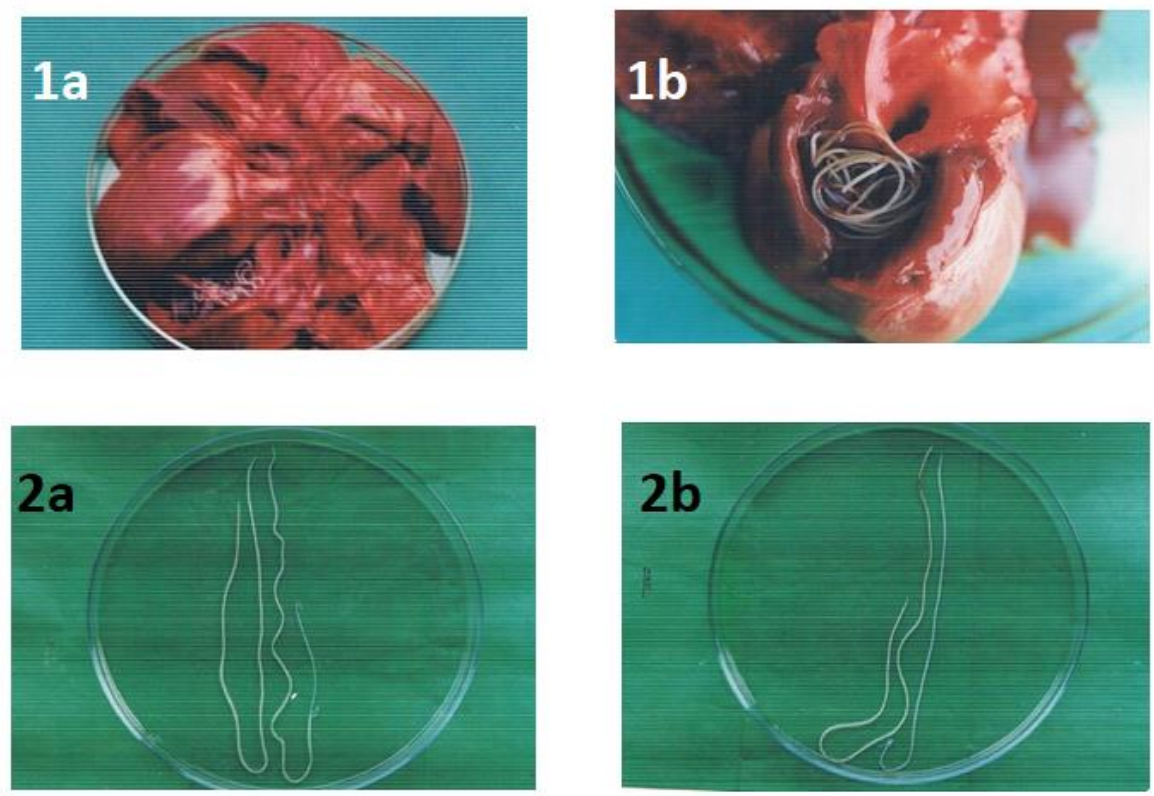

Figures: 1a: Adult Dirofilaria immitis within the right ventricle of the heart of Dog; 1b: Adult Dirofilaria immitis within the right ventricle of the heart of Fox; 2a: Adult Dirofilaria immitis of Dogs in Petridish; 2b: Adult Dirofilaria immitis of Fox in Petridish

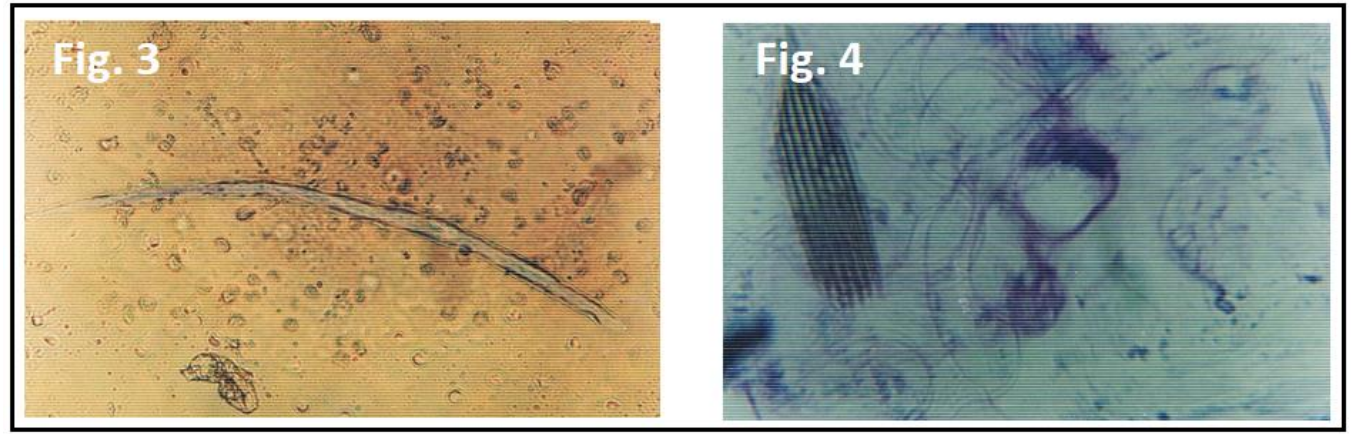

Figure 3. Microfilariae ( $\mathrm{mf}$ ) in the blood smear slide of Dog under microscope; Figure 4. Microfilariae from haemocoele of Culex sp (Female) under microscope

\section{DISCUSSION}

Our study recorded the prevalence of $D$. immitis among dogs and foxes in Bangladesh. Age wise recording illustrated that $46.1 \%$ young dog and $66.6 \%$ adult dogs were infected and in foxes $66.6 \%$ young and $75.0 \%$ adult were infected (Table 2). These conform to the finding of $D$. immitis only in dogs in Bangladesh (Ahmed, 1976; Shaikh and Haq, 1984; Rahman, 1992). The prevalence of $D$. immitis in the Mymensingh Municipal Area was considered very high and commensurate with findings in other countries as recorded in Naha City Okinawa (Suenaga et al., 1976), in USA (Acevedo and Theis, 1981; Walters and Lavoipierre, 1984), in Japan (Hatsushika et al., 1992), in Canada (Slocombe and Villeneuve, 1993), in Italy (Ryan et al., 1995). All these above authors had denoted higher prevalence by $20.0 \%$ and above in dogs as a serious threat to health of man. None of these authors had studied prevalence of $D$. immitis in wild carnivores like foxes. 
In Bangladesh, incidence of $D$. immitis in foxes was recorded in a report (Rahman, 1992) but none of $D$. immitis in jackals was reported in other reports (Shaikh and Haq, 1984). Whereas in the study areas, dogs and foxes had been found infected at a much higher incidence and these animals lived near the human habitations in the study areas. That is why it is considered a serious public health threat to man and may act as the principal reservoir of $D$. immitis in the area.

Prevalence of $D$. immitis in cats in many countries had been recorded (Deem et al., 1998; Smith et al., 1998; Saito et al., 1995; Roncalli et al., 1998; Genchi et al., 1995). One of the research succeeded in making stimulated transmission of $D$. immitis in cat through the bite of infected mosquitoes in USA (Monsour et al., 1995). In the study area none of 15 cats examined were found infected; reasons for absence of such infection status might be the vector mosquito species not normally biting the cats concerned mosquito species were infection free in the locality.

Age and sex wise infection in dogs/foxes were found insignificant $(P>0.05)$ which indicated that dogs and foxes were equally susceptible to $D$. immitis infection perhaps due to their wild habitat.

Presence of $\mathrm{mf} 1$ in the peripheral blood was considered significant $(\mathrm{P}<0.01)$. This indicated that all dogs and foxes carried $\mathrm{mf} 1$ with increased probability for vector mosquitoes to pick up $\mathrm{mf} 1$. This statement was substantiated by the detection of $\mathrm{mf} 3$ in the hemocoele of mosquitoes such as $11.3 \%$ in Culex sp, and 6.1 $\%$ in Anopheles sp.

This detection of $D$. immitis M-3 in Culex sp and Anopheles sp was relevant to findings by several authors (Todaro and Morris, 1975; Lewandowski, 1977; Hansen and Grant, 1978; Buxton and Mullen, 1980; Pinger, 1982; Walters and Lavoipierre, 1982; Roberts, 1985; Wright and Boyce, 1989; Russel, 1985; Jones and Meisch, 1993) who implicated these two genera of mosquitoes in the transmission of $D$. immitis. But unlike the findings by some of the above authors, none of the 210 Aedes sp of mosquitoes examined during this study were positive to microfilariae of $D$. immitis. This could probably due to collection of few Aedes sp or collection time was not appropriate for abundance of Aedes sp. None of the authors had quantified the rate of infection by mosquitoes which were considered very important as a prelude by epizootiological point of view.

\section{CONCLUSIONS}

This study established the fact that the Mymensingh Municipal area is a highly endemic area for $D$. immitis infection in dogs and foxes. Besides suffering from dirofilariasis, these canines also act as reservoir of infection for man since $D$. immitis is transmitted to man by the vector mosquitoes like Culex sp. and Anopheles $\mathrm{sp}$. with higher probability of developing pulmonary eosinophilia. Because of both veterinary and public health significance, further detailed studies on the prevalence of $D$. immitis in other region of the country are highly recommended.

\section{ACKNOWLEDGEMENT}

This work was financially supported by the University Grants Commission (UGC), Govt. of Bangladesh. We gratefully acknowledge the cooperation for trapping dogs, cats and foxes from the community area of Mymensingh.

\section{CONFLICT OF INTERST}

There is no conflict of interests. 


\section{REFERENCES}

1. Acevedo $\mathrm{R}$ and Theis $\mathrm{JH}, 1980$. Report of a preliminary survey in countries of California to assess the prevalence of heartworm in dogs. California Veterinarian, 15-16.

2. Ahmed AKNU, 1976. Blood parasites of domestic Animals in Bangladesh. Bangladesh Veterinary Journal, 10(1-4): 69-71.

3. Belding DL, 1965. Textbook of Parasitology. $3^{\text {rd }}$ ed. (Appleton Century Crofts) New York, 504-543.

4. Bickley WE, Tawrence RS, Ward GM and Shilinger RB, 1977. Dog to dog transmission by Aedes canadensis. Mosquito News, 37(1): 137-138.

5. Buxton BA and Mullen GR, 1980. Field isolation of Dirofilaria from mosquitoes in Alabama. Journal of Parasitology, 66(1): 140-144.

6. Cable RM, 1953. An illustrated laboratory manual of Parasitology. Burgess Publishing Co. Menneapolis 15, Minnesota, 23-23.

7. Chandler AC and Read CP, 1961. Introduction to parasitology. John Willey and Sons, Inc. N. Y.

8. Deem SL, Heard DJ and LaRock R, 1998. Heartworm (D. immitis) disease and golomerulonephritis in a black-footed cat (Felwasnigripes). Journal of Zoo and Wildlife Medicine, 29(2): 199202.

9. Genchi CG, Venco B and Di Sacco, 1995. Cat heartworm (D. immitis) infection in Italy, spread and Prophylactic, Treatment, 15th International Conference of the World Association for the Advancement of Vet. Parasitology. Aug 30-Sept 2, Yokohama, Japan.

10. Hansen CP and Grant CD, 1978. The sudden rise of dog heartworm (D. immitis) to a serious pest level in San Mateo country. Proceeding and papers on the forty-sixth Annual conference of the California mosquito and vector control association, Inc. January 29-February 1, 15-16.

11. Hatsushika R, Okino T, Shimizu M and Ohyama F, 1992. The prevalence of dog heartworm D. immitis infection in stray dogs in Okayama, Japan. Kawasaki Medical Journal, 18 (3-4): 75-83.

12. Hoeden $\mathrm{J}$ and Van der, 1964. Zoonoses Elsevier pub. New York, 529-60.

13. Jones JW and Meisch MV, 1993. Potential mosquito vectors of dogs heartworm, D. immitis in eastern Arkansas. Southwestern-Entomologist, 19-23.

14. Lewandowski HHJR, 1977. Determination of the heartworm in Michigan. Dissertation-AbstractsInternational, 38B (5): 2028-2029.

15. Mansour AE, McCall JW, McTier TL, Supakorndej N, Ricketts R, Soil MD and Knight DH, 1995. Epidemiology of feline Dirofilariasis infections induced by simulated natural exposure to Aedes aegypti experimentally infected with heartworms. Proceeding of heartworm symposium 95, Auburn, U.S.A., 31, Mrach-2nd April, 87-95.

16. Newton $W L$ and Wright $W H, 1956$. The occurrence of a dog filariid other than $D$. immitis in the United States. Journal of Parasitology, 42: 246-258.

17. Pinger RR, 1982. Presumed D. immitis infections in Mosquito (Diptera Culicidae) in Indiana. U.S.A. Journal of Medical Entomology, 19 (5): 553-555.

18. Rahman MH, 1992. Studies on the Epidemiology of filariid worms of animals and their zoonotic significant. Final Report by University Grants Commission, Sher-EBangla Nagar, Dhaka-1207, 1-2.

19. Roberts EP, 1985. A study of dog heartworm (D. immitis) in the Baltimore Washington area. Dissertation Abstracts International-B, 45 (11): 3418.

20. Roncalli RA, Yamane $Y$ and Nagata I, 1998. Prevalence of $D$. immitis in cats in Japan. Veterinary- Parasitology, 75 (1): 81-89.

21. Russell RC, 1985. The relative importance of various mosquitoes for the transmission and control of dog heartworm in south-eastern Australia. Australian Veterinary Journal, 67 (5): 191-192.

22. Ryan WG, Newcomb KM, Soll MD and Knight DH, 1995. Prevalence of feline heartworm disease a global review. Proceeding of the Heartworm Symposium, 1995, Auburn, Alabama, U.S.A., 31, March-April, 79-86.

23. Saito I, Yamaguchi H, Yoshida K, Kusaura J, Wada E, Morishige K and longu Y, 1995. Prevalence of parasites in domestic dogs and cats in Fukuyama City, Japan, in. Journal-of Veterinary-Meidicine-, Japan, 51(11): 889-892. 
24. Shaikh H and Haq MM, 1984. Zoonotic parasites of Bangladesh. Report by Dept. of Parasitology, Bangladesh Agricultural University, Mymensingh, 1- 17.

25. Slocombe JOD and Villeneuve A, 1993. Heartworm on dogs in Canada in 1991. Canadian Veterinary Journal, 34 (10): 630-633.

26. Smith JW, Scott Moncrieff JC and Revers BJ, 1998. Pneumothorax secondary to D. immitis infection in two cats. Journal of the American Veterinary Medical Association, 213 (1): 91 93.

27. Soulsby EJL, 1982. Helminthes, Arthropods and Protozoa of Domesticated Animals. $7^{\text {th }}$ ed. Bailliere Tindall and Cassell Ltd, London, 307-310.

28. Suenaga O, Kuniyoshi SE, Kishimoto T, Ura M and Ohshiro N, 1976. A survey of canine filariasis on Okinawa upon of the island to Japan in 1972. Tropical Medicine, 18 (4): 183-194.

29. Swaroop S, Gilroy AB and Umera K, 1966. Statistical methods in Malaria Eradication. WHO, Geneva.

30. Todaro W and Morris CD, 1975. Current status of dog heartworm in central New York. Proceedings Sixtysecond Annual Meeting. The American Mosquito Control Association, Atlantic City, New Jersey, 11-14 March, 62:58.

31. Walters LL and Lavoipierre MMJ, 1982. Vector potential of six mosquito species in landscapes of high heartworm endemicity in northern California. Proceeding and papers of the forty-ninth-Annual conference of the California Mosquito and Vector Control Association. Inc. April 26-29, Red lion Motor Inn, Redding California, 9.

32. Walters LL and Lavoipierre MMJ, 1984. Landscape Epidemiology of mosquito-borne canine heartworm (D. immitis) in northern California, U.S.A. Community based surveys of domestic dogs in three landscapes. Journal of Entomology, 21:1-16.

33. Wright SA and Boyce KW, 1989. Epizootiology of canine cardiovascular Dirofilariasis in six northern California countries. Proceeding papers of the Annual conference of the California Mosquito and vector control Association, Publ, 57: 37-43.

34. Yamaguti S, 1961. Systema Helminthum, Vol. III: The Nematodes of vertebrates. Part-I New York, Interscience publisher's, 637-666. 